Frontiers in Heat and Mass Transfer

\title{
EFFECTS OF BUOYANCY PARAMETER ON UNSTEADY 3D DOUBLE DIFFUSIVE CONVECTION IN MOLTEN PB-SN ALLOYS
}

\author{
Maatki Chemseddine ${ }^{\mathrm{a}}$, Hakan F. Oztop ${ }^{\mathrm{b}, \mathrm{c}, *}$, Lioua Kolsi ${ }^{\mathrm{a}, \mathrm{d}}$, Abdullah A.A.A. Al-Rashed ${ }^{\mathrm{e}}$, Mohamed Naceur Borjini ${ }^{\mathrm{a}}$, Nidal Abu-Hamdeh \\ ${ }^{a}$ Unité de Recherche de Métrologie et des Systèmes Energétique, Ecole Nationale d'Ingénieurs, Monastir, University of Monastir, Tunisia \\ ${ }^{b}$ Department of Mechanical Engineering, Technology Faculty, Firat University, Elazig, Turkey \\ ${ }^{c}$ Department of Mechanical Engineering, Engineering College, King Abdulaziz University, Jeddah, Saudi Arabia \\ ${ }^{d}$ College of Engineering, Mechanical Engineering Department, Haïl University, Haïl City, Saudi Arabia \\ ${ }^{e}$ Dept. of Automotive and Marine Engineering Technology, College of Technological Studies, The Public Authority for Applied Education and
}

Training, Kuwait

\begin{abstract}
A computational study has been made for a three dimensional double diffusive convection with molten $\mathrm{Pb}$-Sn by using finite volume method. In this work, two vertical walls have different temperature and different concentration while remaining walls are adiabatic. Buoyancy ratio, which changes between $\mathrm{N}=-0.1$ and -10 , is the main governing parameter during work. Other parameters are taken as fixed with $\operatorname{Pr}=0.02, \mathrm{Le}=7500$ and $\mathrm{Ra}=$ $5 \times 10^{3}$. It is found that changing of buoyancy parameter becomes more effective on heat transfer than that of mass transfer.
\end{abstract}

Keywords: double diffusive, natural convection, molten $\mathrm{Pb}-\mathrm{Sn}$, heat transfer, numeric

\section{INTRODUCTION}

In engineering applications, double diffusive convection problems finds important place such as geophysical flows, the migration of moisture in fibrous insulation, bio-chemical contaminants transport in the environment, underground disposal of nuclear wastes, crystal growth processes and different metalurgical applications.

Hydromagnetic double-diffusive convection of a radiatively participating fluid inside a rectangular enclosure is studied computationaly by Borjini et al. (2005). They observed that the oscillatory flow, due to competition between compositional and thermal buoyancy forces, occurs only in thermally dominated flow and can be damped and stabilized by increasing of the external magnetic field. This increasing diminishes the delay between the two compositional recirculations, which seems to be necessary to the stabilization process.

Nishimura et al. (1994) describes the occurrence and development of double-diffusive convection in the liquid phase during solidification of $\mathrm{NH} \& \mathrm{H}_{2} \mathrm{O}$ in a cavity with lateral cooling. They observed that the concentration in each cell becomes nearly constant, except for the initial development of cells. The fluid in the diffusive interface is initially constant, but the interface changes into a new cell under a fixed condition. A 3D numerical analysis by using vorticity-vector potential formulations with finite-volume method has been performed to study the double-diffusive convection in a stack of cubic enclosures by Abidi et al. (2008). Their findings showed that the effect of heat and mass diffusive walls differs between the case of thermally dominated flow and the compositionally dominated one. The effect of double-diffusive natural convection of water in a partially heated closed space with Soret and Dufour coefficients around the density maximum is studied by Nithyadevi and Yang (2009) by using control volume technique. They calculated the flow pattern and heat and mass transfer for different governing parameters.

Gholizadeh et al. (2016) studied of double-diffusive natural convection in a trapezoidal enclosure with a partial heated active right sidewall by using the finite difference method. Wang et al. (2016) made a work on oscillatory double-diffusive convection in horizontal cavity with Soret and Dufour effects. They used SIMPLE algorithm with QUICK scheme in non-uniform staggered grid distribution. They showed that double-diffusive convection develops from steady-state convection-dominated, periodic oscillatory, quasi-periodic oscillatory to chaotic flow, and finally return to periodic oscillation as buoyancy ratio increases. Bardan et al. (2000) solved nonlinear double diffusive convection problem in $2 \mathrm{D}$ closed spaces driven by lateral temperature and concentration differences with a combination of both analytical and numerical techniques. Maatki et al. (2016) thermosolutal convection of fluid in a cubic closed space filled with a binary mixture is studied. They used the formalism vector potential vorticity in a threedimensional configuration by using the finite volume method. They observed that the moderate increase in the Ha number, decreases the amplitude of the transversal component. Maatki et al. (2014) studied the effect of the magnetic field inclination on three dimensional double diffusive convection in a cubical closed space filled with binary mixture. They showed that the increasing of the inclination angle of the magnetic field damped the flow.

Ibrahim and Lemonnier (2010) worked on the coupling of transient double diffusive convection with radiation numerically in a square closed space filled with a mixture of $\mathrm{N}_{2}$ and $\mathrm{CO}_{2}$. They found that the gas radiation modifies the structure of the velocity and thermal fields and accelerates the convergence to steady state in aiding case. Maatki et al. (2013) present a computational treatment of a double diffusive convection in a three dimensional closed space filled with a binary mixture. In their study, the vertical walls are given different temperatures and concentrations by using finite volume method. They observed that increasing of the intensity of the magnetic field causes a monotonic reduction of intensities of the main and three dimensional transverse flows. Entropy generation of double diffusive natural convection is analyzed for a three dimensional differentially heated closed space by Maatki et al. (2013). They showed that both Ra number and buoyancy ratio play dominant role on entropy generation and heat and mass transfer. Teamah (2008) worked computationally on doublediffusive convective laminar flow in a rectangular closed space with the

* Corresponding Author: E-mail : hfoztop1@gmail.com 
upper and lower surfaces being insulated including uniform magnetic field in the presence of heat generation or absorption. He found that the average $\mathrm{Nu}$ and $\mathrm{Sh}$ numbers have minimum values at buoyancy ratio as $N=1$.

Ghenai et al. (2003) made experimental study on the solidification of a binary mixture of ammonium chloride and water $\left(\mathrm{NH}_{4} \mathrm{Cl}-\mathrm{H}_{2} \mathrm{O}\right)$ in a differentially heated closed space. Their main aim was to investigate the effect of the initial concentration of ammonium chloride on the solidification. They used PIV technique in their experiments. They observed that the growth rate of the frozen layer is almost double at the bottom of the cavity. Ghachem et al. (2012) obtained numerical results by using finite volume method of double-diffusive natural convection in a 3D solar distiller for laminar flow. Also, they obtained entropy generation results. They found that the variation of the buoyancy ratio affects significantly the distributions of isotherms, iso-concentrations and the structure of the flow. The flow structure is $3 \mathrm{D}$ at $\mathrm{N}=1$. Other related works can be found in references of Sheikholeslami (2017a and 2017b), Sheikholeslami and Chamkha (2017), Sheikholeslami and Rokni (2017a and 2017b) and Sheikholeslamia and Shehzad (2017).

The main objective of this paper is to simulate the three dimensional diffusive convection for molten $\mathrm{Pb}-\mathrm{Sn}$ by using a computational technique. The problem of molten alloy in three dimensional closed space is still not extensively studied in literature In this computational work, a study is proposed to analyse the double diffusive natural convection with horizontal temperature and concentration gradients in a $3 \mathrm{D}$ closed space for different buoyancy ratio in wide range.

\section{DEFINITION OF PHYSICAL MODEL}

Physical model is presented in Fig. 1 with boundary conditions and coordinates. The closed space is mainly a cubical cavity. The left side of the cavity has height concentration and hot wall while the right side of the cavity has cold wall and low concentration and remaining walls are adiabatic. The gravity acts in negative y direction. The fluid contained in the cavity is assumed incompressible and the flow follows the Boussinesq approximation.

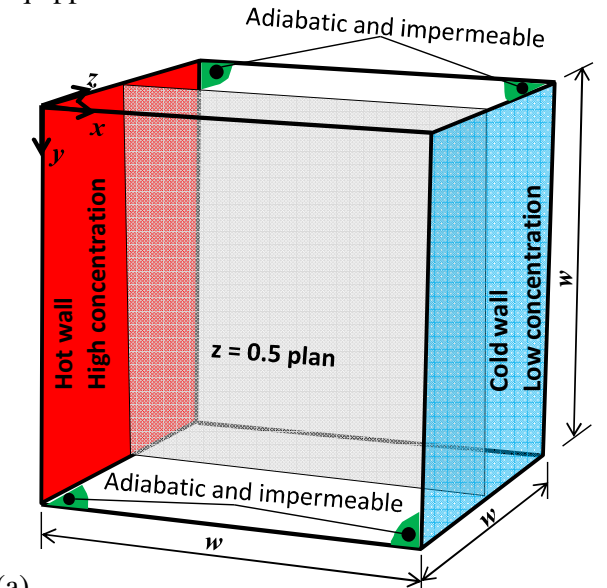

(a)

$$
\begin{gathered}
\frac{\partial T}{\partial x}=0 ; \frac{\partial C}{\partial x}=0 \\
\mathrm{Z}=0.5 \text { plan } \\
\frac{\partial T}{\partial x}=0 ; \frac{\partial C}{\partial x}=0
\end{gathered}
$$

Fig. 1 Considered physical model, boundary conditions and coordinates; (a): $3 \mathrm{D}$ configuration; (b) $\mathrm{z}=0.5$ plan

\section{CALCULATIONS}

The equations describing the double diffusive natural convection are the conservation of mass Eq.(1), momentum Eq.(2), energy Eq.(3) and species diffusion Eq.(4) as:

$$
\begin{gathered}
\nabla \cdot \vec{V}^{\prime}=0 \\
\frac{\partial \vec{V}^{\prime}}{\partial t^{\prime}}+\left(\vec{V}^{\prime} \cdot \vec{\nabla}\right) \vec{V}^{\prime}=-\frac{1}{\rho} \vec{\nabla} P^{\prime}+v \Delta \vec{V}^{\prime} \\
\quad+\beta_{t}\left(T^{\prime}-T_{0}\right) \vec{g}+\beta_{c}\left(C^{\prime}-C_{0}\right) \vec{g} \\
\frac{\partial C^{\prime}}{\partial t^{\prime}}+\vec{V}^{\prime} . \nabla C^{\prime}=D \nabla^{2} C^{\prime} \\
\frac{\partial T^{\prime}}{\partial t^{\prime}}+\vec{V}^{\prime} \cdot \nabla T^{\prime}=\alpha \nabla^{2} T^{\prime}
\end{gathered}
$$

In order to eliminate the pressure terms, we had recourse to the vorticity-vector potential formalism $(\vec{\psi}-\vec{\omega})$ in a 3-D configuration.

The vector potential and the vorticity are, respectively, defined by the two following relations:

$$
\vec{\omega}^{\prime}=\vec{\nabla} \times \vec{V}^{\prime} \text { and } \vec{V}^{\prime}=\vec{\nabla} \times \vec{\psi}^{\prime}
$$

In the equations $\left(1,2,3,4\right.$ and 5), time $t^{\prime}$, velocity $\vec{V}^{\prime}$, the stream function $\vec{\psi}^{\prime}$, the vorticity $\vec{\omega}^{\prime}$, are put respectively in their dimensionless forms by $W^{2} / \alpha, \alpha / W, \alpha$ and $W^{2} / \alpha$ : and the dimensional temperature and concentration are respectively defined by:

$$
T=\left(T^{\prime}-T_{c}{ }^{\prime}\right) /\left(T_{h}{ }^{\prime}-T_{c}{ }^{\prime}\right) \text { and } C=\left(C^{\prime}-C_{l}{ }^{\prime}\right) /\left(C_{h}{ }^{\prime}-C_{l}{ }^{\prime}\right) \text {. }
$$

By application of the $(\vec{\psi}-\vec{\omega})$ formalism, the dimensionless governing equations for the conservation of mass, momentum, energy and species diffusion, together in the Cartesian coordinates system $(\mathrm{x}, \mathrm{y}, \mathrm{z})$, are written as follow:

$$
-\vec{\omega}=\nabla^{2} \vec{\psi}
$$

$$
\begin{gathered}
\frac{\partial \vec{\omega}}{\partial t}+(\vec{V} . \nabla) \vec{\omega}-(\vec{\omega} \cdot \nabla) \vec{V}= \\
\Delta \vec{\omega}+\operatorname{Ra} \operatorname{Pr}\left[\frac{\partial T}{\partial z}-N \frac{\partial C}{\partial z} ; 0 ;-\frac{\partial T}{\partial x}+N \frac{\partial C}{\partial x}\right] \\
\frac{\partial T}{\partial t}+\vec{V} \cdot \nabla T=\nabla^{2} T \\
\frac{\partial C}{\partial t}+\vec{V} \cdot \nabla C=\frac{1}{L e} \nabla^{2} C
\end{gathered}
$$

Where $\operatorname{Pr}=v / \alpha$ is the Prandtl number, $R a=\frac{g \beta_{t} W^{3}\left(T_{h}^{\prime}-T_{c}^{\prime}\right)}{\alpha v}$ the Rayleigh number, $N=\frac{\beta_{c}\left(C_{h}^{\prime}-C_{l}^{\prime}\right)}{\beta_{t}\left(T_{h}^{\prime}-T_{c}^{\prime}\right)}$ is the ratio of buoyancy forces, and $L e=\frac{\alpha}{D}=\frac{S c}{\operatorname{Pr}}$ the Lewis number ( $\mathrm{Sc}$ is the Schmidt number).

Thermal and diffusive gradient between the active walls of the cavity causes entropy generation in the system. The local entropy generation in a three-dimensional flow is given by: 


$$
\begin{aligned}
& S_{\text {gen }}^{\prime}=\left\{\frac{k}{T_{0}^{2}}\left[\left(\frac{\partial T^{\prime}}{\partial x^{\prime}}\right)^{2}+\left(\frac{\partial T^{\prime}}{\partial y^{\prime}}\right)^{2}+\left(\frac{\partial T^{\prime}}{\partial z^{\prime}}\right)^{2}\right]\right\}+ \\
& \frac{\mu}{T_{0}}\left\{\begin{array}{l}
2\left[\left(\frac{\partial u_{1}^{\prime}}{\partial x^{\prime}}\right)^{2}+\left(\frac{\partial u_{2}^{\prime}}{\partial y^{\prime}}\right)^{2}+\left(\frac{\partial u_{3}^{\prime}}{\partial z^{\prime}}\right)^{2}\right]+ \\
+\left\{\begin{array}{l}
\left.\frac{\partial u_{2}^{\prime}}{\partial x^{\prime}}+\frac{\partial u_{1}^{\prime}}{\partial y^{\prime}}\right)^{2}+\left(\frac{\partial u_{3}^{\prime}}{\partial y^{\prime}}+\frac{\partial u_{2}^{\prime}}{\partial z^{\prime}}\right)^{2}+\left(\frac{\partial u_{1}^{\prime}}{\partial z^{\prime}}+\frac{\partial u_{3}^{\prime}}{\partial x^{\prime}}\right)^{2} \\
\frac{R D}{C_{0}}\left[\left(\frac{\partial C^{\prime}}{\partial x^{\prime}}\right)^{2}+\left(\frac{\partial C^{\prime}}{\partial y^{\prime}}\right)^{2}+\left(\frac{\partial C^{\prime}}{\partial z^{\prime}}\right)^{2}\right]+ \\
T_{0}\left[\left(\frac{\partial C^{\prime}}{\partial x^{\prime}}\right)+\left(\frac{\partial T^{\prime}}{\partial y^{\prime}}\right)\left(\frac{\partial C^{\prime}}{\partial y^{\prime}}\right)+\left(\frac{\partial T^{\prime}}{\partial z^{\prime}}\right)\left(\frac{\partial C^{\prime}}{\partial z^{\prime}}\right)\right]
\end{array}\right\}
\end{array}\right.
\end{aligned}
$$

Where Co and To are respectively the references concentration and temperature.

The dimensionless local entropy generation can be written as:

$$
N_{S}=N_{s-t h}+N_{s-f r}+N_{s-d i f}+N_{s-t h-d i f}
$$

Where:

$$
\begin{gathered}
N_{S-t h}=\left[\left(\frac{\partial T}{\partial x}\right)^{2}+\left(\frac{\partial T}{\partial y}\right)^{2}+\left(\frac{\partial T}{\partial z}\right)^{2}\right] \\
N_{S-f r}=\varphi_{1} \cdot\left\{\begin{array}{l}
\left.2\left(\frac{\partial u_{1}}{\partial x}\right)^{2}+\left(\frac{\partial u_{2}}{\partial y}\right)^{2}+\left(\frac{\partial u_{3}}{\partial z}\right)^{2}\right] \\
+\left(\left(\frac{\partial u_{2}}{\partial x}+\frac{\partial u_{1}}{\partial y}\right)^{2}+\left(\frac{\partial u_{3}}{\partial y}+\frac{\partial u_{2}}{\partial z}\right)^{2}+\left(\frac{\partial u_{1}}{\partial z}+\frac{\partial u_{3}}{\partial x}\right)^{2}\right]
\end{array}\right\} \\
N_{S-d i f}=\varphi_{2}\left[\left(\frac{\partial C}{\partial x}\right)^{2}+\left(\frac{\partial C}{\partial y}\right)^{2}+\left(\frac{\partial C}{\partial z}\right)^{2}\right] \\
N_{S-t h-d i f}=\varphi_{3}\left[\left(\frac{\partial T}{\partial x}\right)\left(\frac{\partial C}{\partial x}\right)+\left(\frac{\partial T}{\partial y}\right)\left(\frac{\partial C}{\partial y}\right)+\left(\frac{\partial T}{\partial z}\right)\left(\frac{\partial C}{\partial z}\right)\right]
\end{gathered}
$$

Where $N_{S-t h} \cdot, N_{S-f r}, N_{S-d i f}$ and $N_{S-t h-d i f}$ are respectively defined as local dimensionless irreversibility generation due to heat transfer, fluid friction, mass transfer by pure concentrations gradients and mass transfer by mixed product of concentration and thermal gradients.

$\varphi_{1}, \varphi_{2}$ and $\varphi_{3}$ are irreversibility's distribution ratios related to velocity, concentrations and mixed product of concentration and thermal gradients, respectively.

Dimensionless irreversibility distribution ratios $\left(\varphi_{1}, \varphi_{2}\right.$ and $\left.\varphi_{3}\right)$, are given by:

$$
\varphi_{1}=\frac{\mu \alpha^{2} T_{0}}{W^{2} k \Delta T^{\prime 2}} ; \varphi_{2}=\frac{R D T_{0}}{k C_{0}}\left[\frac{\Delta C^{\prime}}{\Delta T^{\prime}}\right]^{2} \text { and } \varphi_{3}=\frac{R D}{k}\left[\frac{\Delta C^{\prime}}{\Delta T^{\prime}}\right]
$$

In the present work, the dimensionless irreversibility ratios are fixed respectively at $\varphi_{1}=10^{-4}, \varphi_{2}=0.5$ and $\varphi_{3}=10^{-2}$ as in Maatki et al. (2014).
Total dimensionless entropy generation is obtained by a numerical integration of dimensionless local entropy generation through the entire volume of the cavity as

$$
\begin{aligned}
& S_{\text {tot }}=\int_{v} N_{s} d v=\int_{v}\left(N_{s-t h}+N_{s-f r}+N_{s-\text { dif }}+N_{s-t h-\text { dif }}\right) d v \\
& S_{\text {tot }}=S_{t h}+S_{f r}+S_{\text {dif }}+S_{\text {th-dif }}
\end{aligned}
$$

The control volume finite difference method is used to discretize Eqs. (6) - (9). The central-difference scheme for treating convective terms and the fully implicit procedure to discretize the temporal derivatives are retained. The grid is uniform in all directions with additional nodes on boundaries. The successive relaxation iterating scheme is used to solve the resulting non-linear algebraic equations. The boundary conditions of the dimensionless parameters are

\section{- Temperature}

$T=1$ at $x=1, T=0$ at $x=0 ; \frac{\partial T}{\partial n}=0$ on other walls

\section{- Concentration}

$C=1$ at $x=1, C=0$ at $x=0 ; \frac{\partial C}{\partial n}=0$ on other walls

\section{- Vorticity}

$$
\begin{gathered}
\omega_{x}=0, \omega_{y}=-\frac{\partial V_{z}}{\partial x}, \omega_{z}=\frac{\partial V_{y}}{\partial x} \text { at } x=0 \text { and } 1 \\
\omega_{x}=\frac{\partial V_{z}}{\partial y}, \omega_{y}=0, \omega_{z}=-\frac{\partial V_{x}}{\partial y} \text { at } y=0 \text { and } 1 \\
\omega_{x}=-\frac{\partial V_{y}}{\partial z}, \omega_{y}=\frac{\partial V_{x}}{\partial z}, \omega_{z}=0 \text { at } z=0 \text { and } 1
\end{gathered}
$$

- $\quad$ Vector potential

$$
\begin{gathered}
\frac{\partial \psi_{x}}{\partial x}=\psi_{y}=\psi_{z}=0 \text { at } x=0 \text { and } 1 ; \\
\psi_{x}=\frac{\partial \psi_{y}}{\partial y}=\psi_{z}=0 \text { at } y=0 \text { and } 1 ; \\
\psi_{x}=\psi_{y}=\frac{\partial \psi_{z}}{\partial z}=0 \text { at } z=0 \text { and } 1
\end{gathered}
$$

- $\quad$ velocity

$$
V_{x}=V_{y}=V_{z}=0 \text { on all walls }
$$

Local Nusselt and Sherwood numbers are given as follows

$$
N u=\left.\frac{\partial T}{\partial x}\right|_{x=0,1} ; S h=\left.\frac{\partial C}{\partial x}\right|_{x=0,1}
$$

The average values of Nusselt and Sherwood numbers, on the isothermal walls are expressed by:

$$
N u_{a v}=\int_{00}^{1} \int_{0}^{1} N u . \partial y . \partial z ; \quad S h_{a v}=\int_{00}^{1} \int_{0}^{1} S h . \partial y . \partial z
$$

\section{VALIDATION OF THE COMPUTER CODE}

The code is validated against the literature result of Bergman and Hyun (1996) by using stream function and concentration as given in Fig. 2. As seen from the figures, obtained both flow field and concentration results and Bergman and Hyun (1996) shows acceptable agreement.

\section{RESULTS AND DISCUSSION}

Double diffusive convection for molten $\mathrm{Pb}-\mathrm{Sn}$ in a cubical cavity for different parameters as Prandtl number, Lewis number, Rayleigh number and buoyancy ratio. Iso-surfacess of temperature, mean Nusselt number and Sherwood number, iso-surfaces of concentration and trajectories are presented for these governing parameters. 

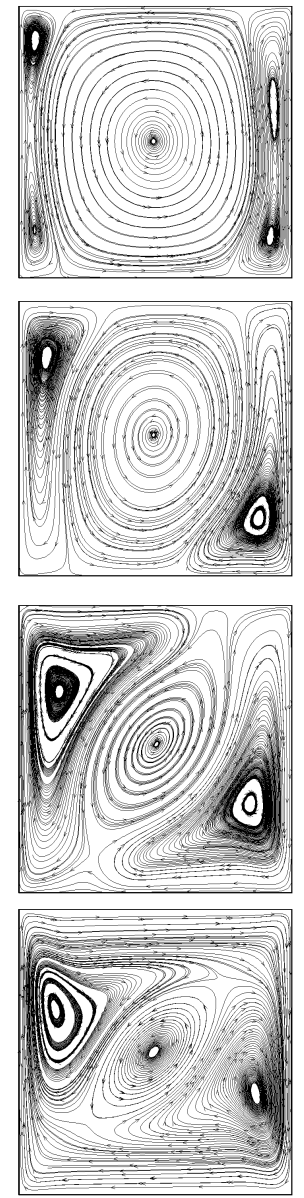

Present results
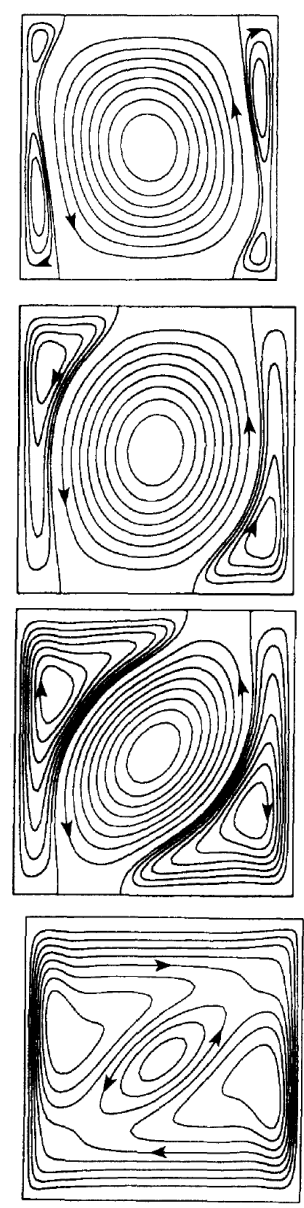

Results of Bergman and Hyun [22]
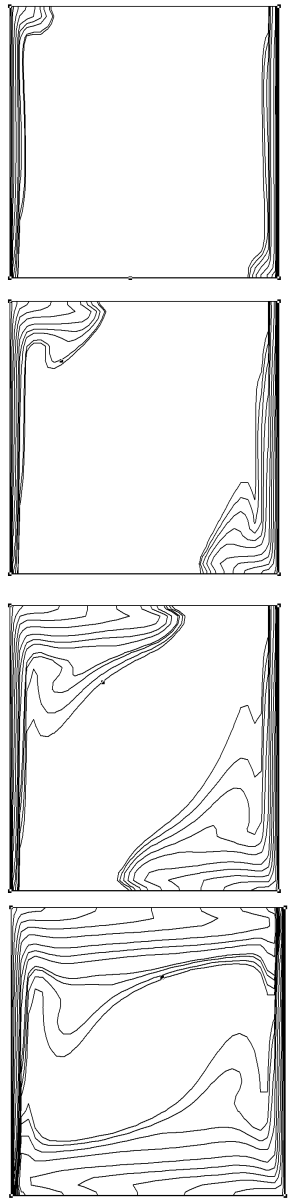

Present results (concentration distribustion)
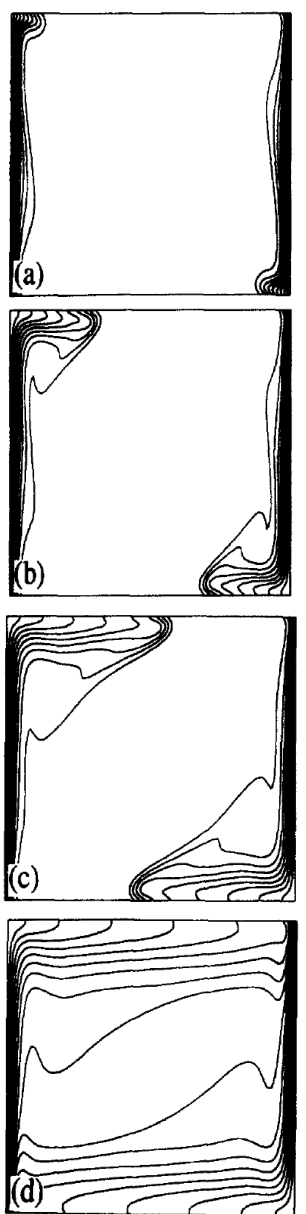

Results of Bergman and Hyun [22]

Fig. 2 Stream function (on the left) and concentration (on the right) distributions for $R a=100, \mathrm{~N}=-10$ at: $(\mathrm{a}) \mathrm{t}=0.3$, (b) $\mathrm{t}=0.75,(\mathrm{c}) \mathrm{t}=1.35$ and (d) $\mathrm{t}=3.15$ for $\operatorname{Pr}=0.02$ and $\mathrm{Le}=7500$
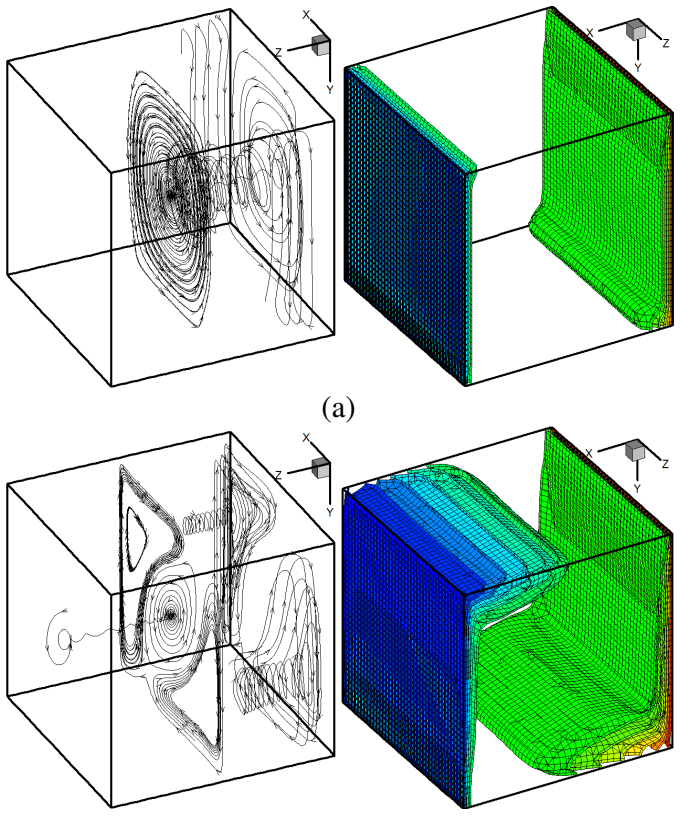

(a)

(c)

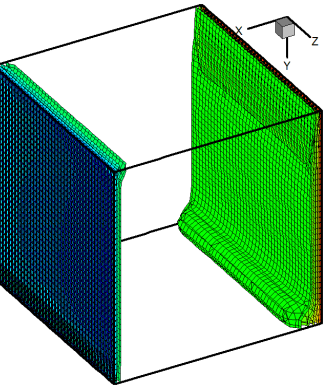

Fig. 3 Particles trajectories and Concentration for $R a=100, N=-10$ at: (a) $t=0.3$, (b) $t=0.75$, (c) $t=1.35$ and $(d) t=3.15$ for $\operatorname{Pr}=0.02$ and $\operatorname{Le}=$

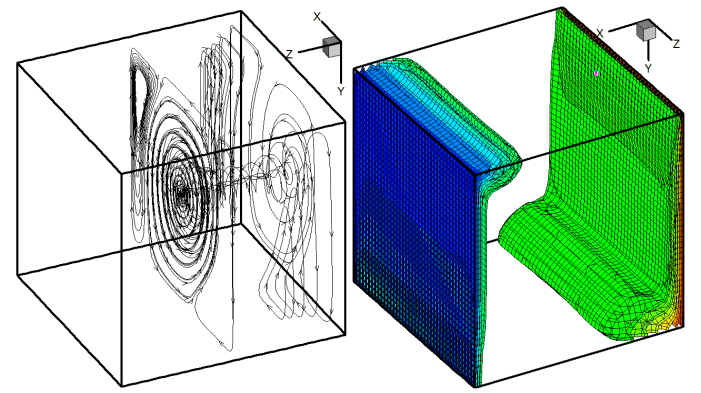

(b)

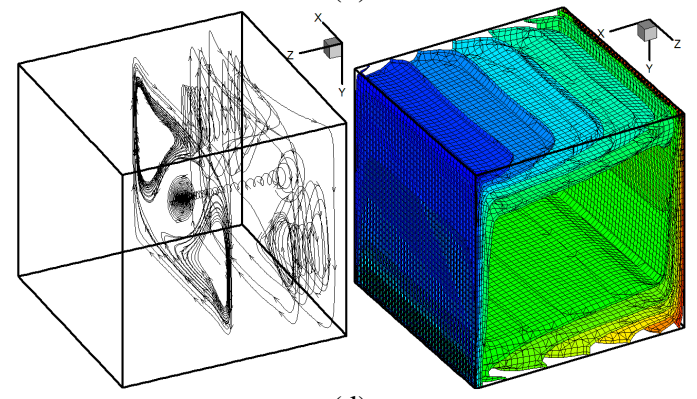

(d) 7500 

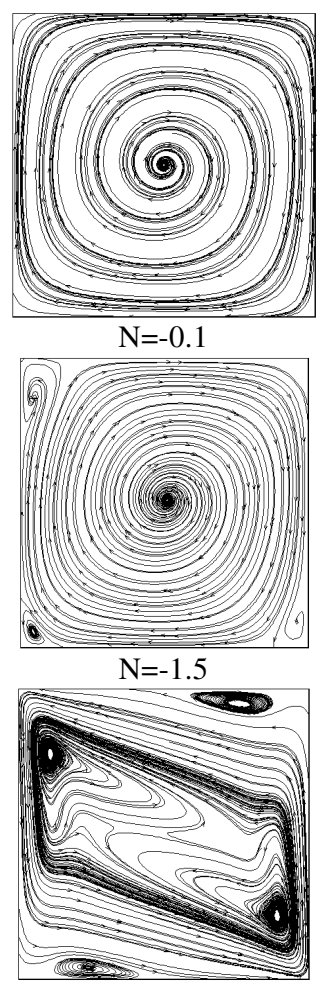

$\mathrm{N}=-3$

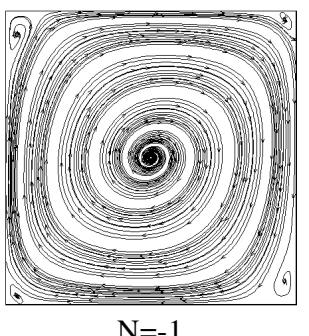

$\mathrm{N}=-1$

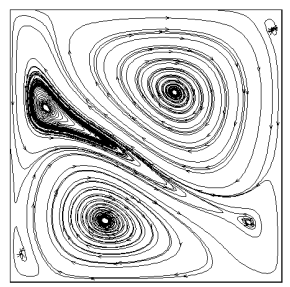

$\mathrm{N}=-2$

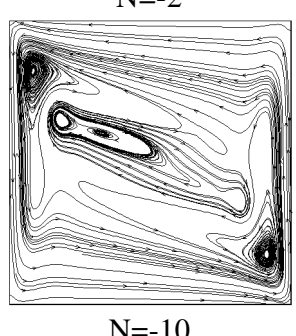

$\mathrm{N}=-10$

Fig. 4 Velocity vector projection in $\mathrm{z}=0.5$ plan for $\operatorname{Pr}=0.02$, Le $=$ $7500, \mathrm{Ra}=5.10^{3}$ and different $\mathrm{N}$
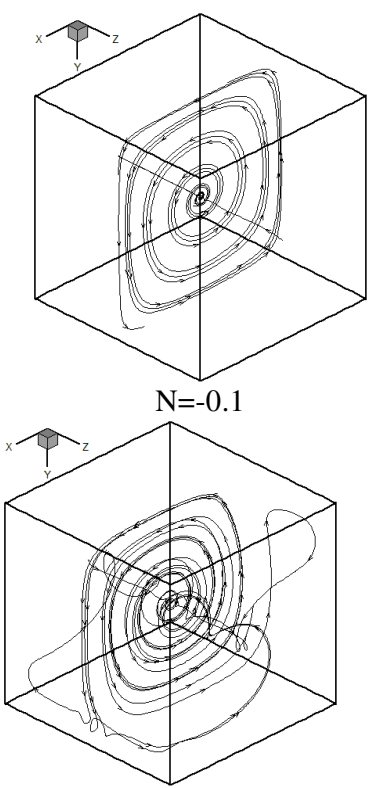

$\mathrm{N}=-1.5$

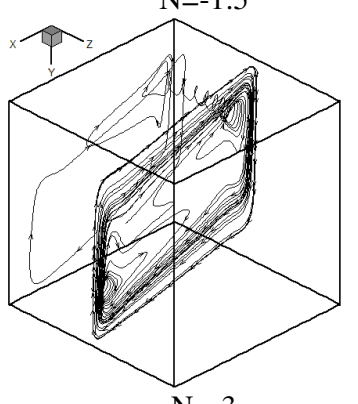

$\mathrm{N}=-3$
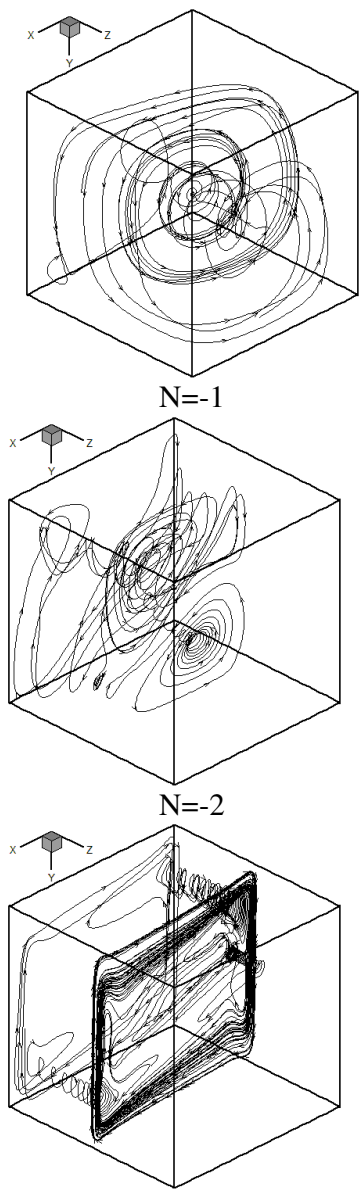

$\mathrm{N}=-10$

Fig. 5 Some particles Trajectories for $\operatorname{Pr}=0.02, \mathrm{Le}=7500$ and $\mathrm{Ra}=$

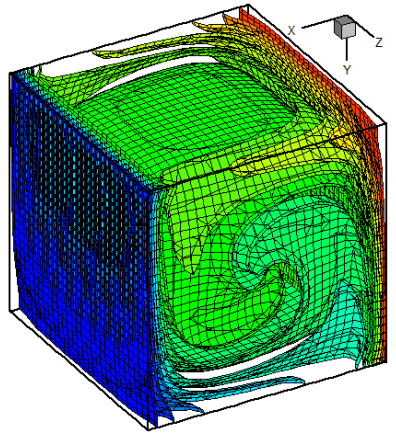

$\mathrm{N}=-0.1$

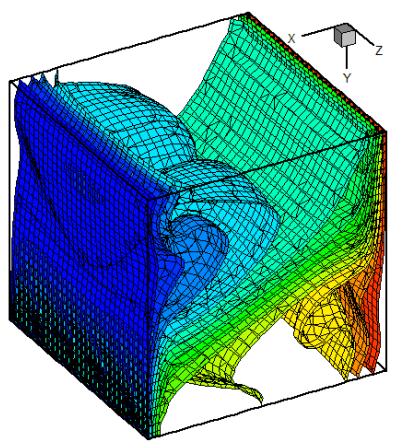

$\mathrm{N}=-2$

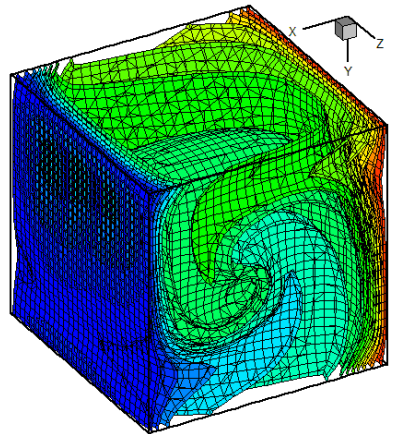

$\mathrm{N}=-1$

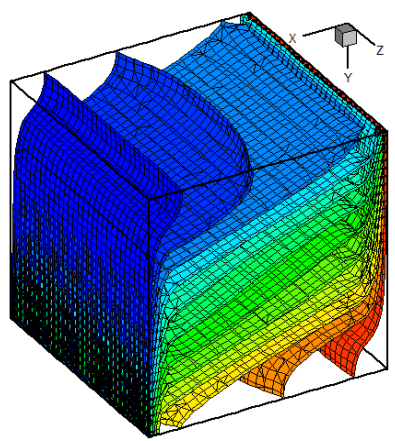

$\mathrm{N}=-3$ $5.10^{3}$ and different $\mathrm{N}$ values

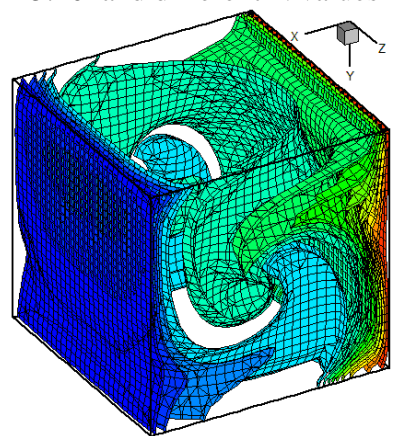

$\mathrm{N}=-1.5$

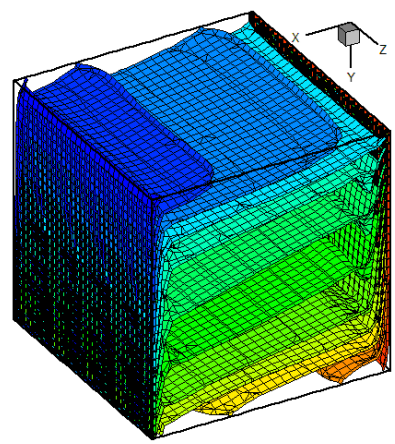

$\mathrm{N}=-10$

Fig. 6 Iso-surfaces of concentration for $\mathrm{Pr}=0.02, \mathrm{Le}=7500$ and $\mathrm{Ra}=5.10^{3}$ and different $\mathrm{N}$ values 
Fig. 3 presents particle trajectories and concentration for $\mathrm{Ra}=100$, $\mathrm{N}=-10$ at different time step and $\mathrm{Pr}=0.02$ and $\mathrm{Le}=7500$. As seen from the figure, the cavity is heated from the right side and concentration is also high at that point. At $t=0.3$, the fluid start to enlarge from the bottom side, and it moves toward to other side with increasing time. In the same manner, the fluid moves from the top side of low concentrated side. For steady-state regime, concentration contours occupies almost whole space. As seen also from particle trajectories, multiple cells are formed inside the closed space and there is a transition from a constant $\mathrm{z}$-plan to another.

Fig. 4 illustrates the effect of $\mathrm{N}$ value for $\mathrm{Pr}=0.02, \mathrm{Le}=7500$ and $\mathrm{Ra}=5 \cdot 10^{3}$. As shown from this figure, number of circulation inside the fluid strongly depended the buoyancy ratio $(\mathrm{N})$. As well known that the buoyancy ratio is defined as the ratio of buoyancy due to concentration difference to buoyancy ratio due to temperature difference. In other words, single cell is formed for $\mathrm{N}=-1$ and -1.5 and cells are formed at corners. The flow shape exhibits a complex distribution but almost parallelogram shaped distribution is observed for $\mathrm{N}=-3$ and -10 (solutally dominated regime). This particle movement can be seen clearly in Fig. 5. Some particle trajectories for $\operatorname{Pr}=0.02$, Le $=7500$ and $\mathrm{Ra}=5.10^{3}$ are presented for different $\mathrm{N}$ values in Fig. 5. As seen from the figure, single circulation cell is formed and it shows almost twodimensional variation. In case of $\mathrm{N}<-1$, different circulation cells are formed especially at corners. For $\mathrm{N}=-3$ and -10 diagonal variation is obtained in center of the closed space.

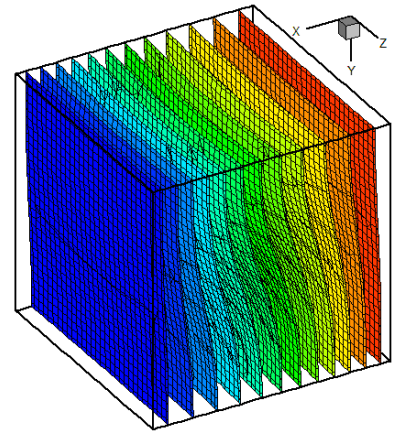

$\mathrm{N}=-0.1$

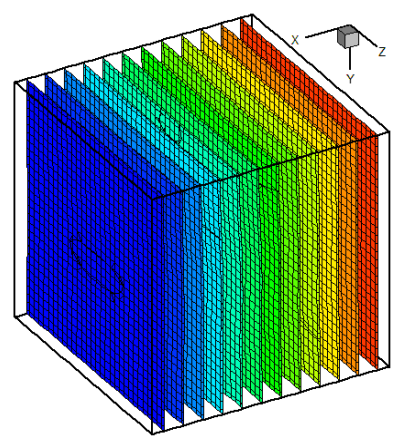

$\mathrm{N}=-2$

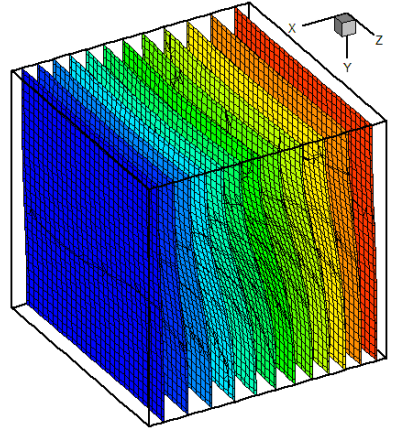

$\mathrm{N}=-1$

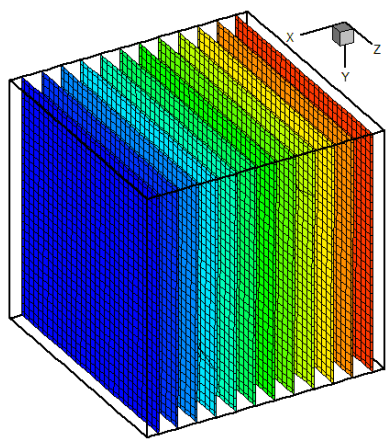

$\mathrm{N}=-3$

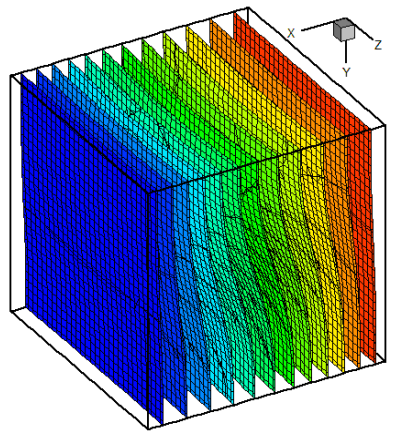

$\mathrm{N}=-1.5$

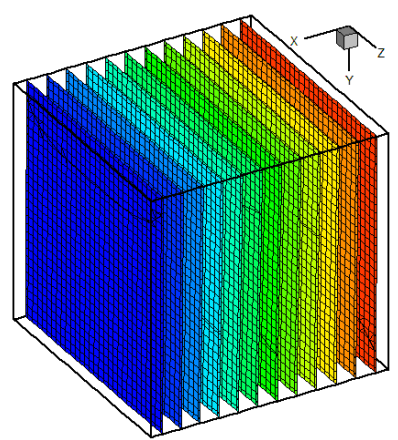

$\mathrm{N}=-10$

Fig. 7 Iso-surfaces of temperature for $\mathrm{Pr}=0.02, \mathrm{Le}=7500$ and $\mathrm{Ra}=5.10^{3}$ and different $\mathrm{N}$ values

Fig. 6 displays the iso-surface concentration at $\mathrm{Pr}=0.02$, Le $=$ 7500 and $\mathrm{Ra}=5.10^{3}$ are presented for various $\mathrm{N}$ values. As can be seen from the figure, concentration distribution becomes chaotic for the absolute lower value of buoyancy ratio up to $\mathrm{N}=-2$. For the lower values of $\mathrm{N}$, namely $\mathrm{N}<1$, the flow is mainly conducted by thermal volume forces. The fluid flow is characterized by thermal vortex in the core region of the closed space shifted toward the right active wall (cold surface with light concentration) and turning clockwise direction. Isosurfaces of temperature is presented for different $\mathrm{N}$ values at $\mathrm{Pr}=0.02$, $\mathrm{Le}=7500$ and $\mathrm{Ra}=5.10^{3}$ in Fig. 7. Temperature distribution is almost same for $\mathrm{N}=-2$ to $\mathrm{N}=-10$. It means that changing of lower $\mathrm{N}$ values becomes insignificant on temperature distribution. As seen from the figure, temperature distribution becomes almost constant for $\mathrm{N} \geq-2$. Temperature contours are distorted for the higher $\mathrm{N}$ values.

Fig. 8 is plotted to show the variation of mean Nusselt number and Sherwood number with $\mathrm{N}$ values. It is seen from the figure that Mean Nusselt number is decreased up to $\mathrm{N}=0$ and it increases with increasing of positive values of $\mathrm{N}$ values. On the contrary, Sherwood number becomes almost constant for all values of $\mathrm{N}$ parameter. Fig. 9 illustrates the local entropy generation due to concentration gradient irreversibility for the parameters of $R a=100, \mathrm{~N}=-10, \mathrm{Pr}=0.02$ and Le $=7500$ at different time steps. At the beginning of the time, the fluid started to penetrate into the cavity started from left top and right bottom side. They are almost parallel to each other. Penetration of entropy generation contours increases with increasing of time. And then, distribution of entropy contours turn to left bottom and right top corners.

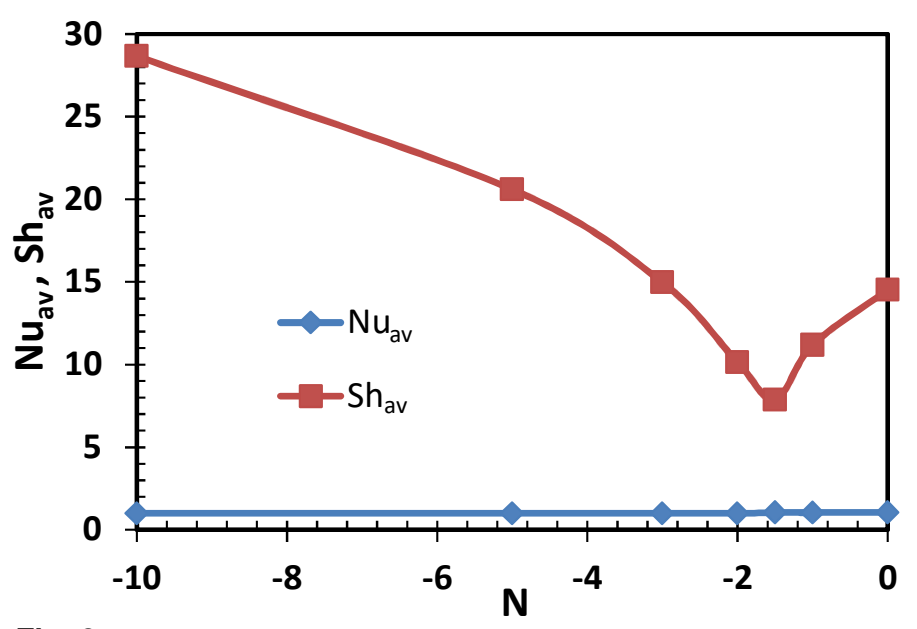

Fig. 8 Variation mean Nusselt and Sherwood number for different $\mathrm{N}$ values at $\mathrm{Ra}=5.10^{3}$ 


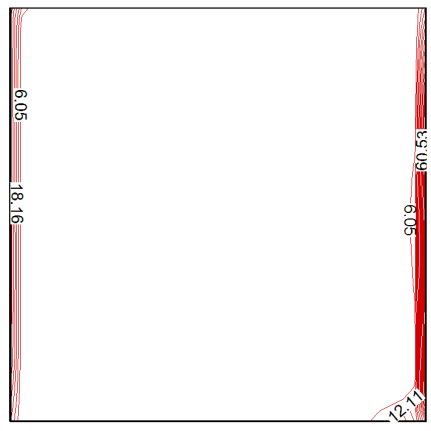

(a)

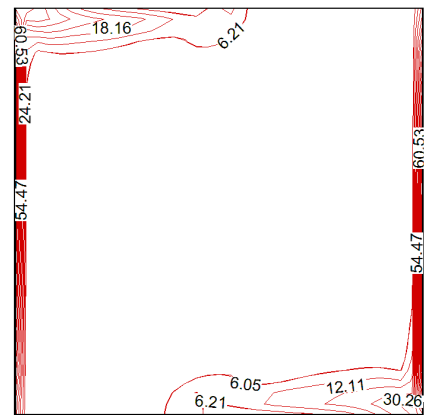

(c)

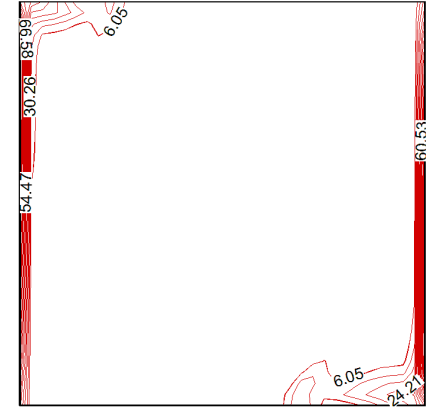

(b)

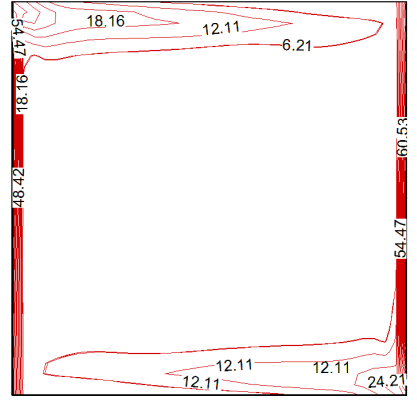

(d)

Fig. 9 Local Entropy generation due to concentration gradient irreversibility $N_{S \text {-dif }}$ for $R a=100$ and $\mathrm{N}=-10$ at (a) $\mathrm{t}=0.3$, (b) $\mathrm{t}=$ 0.75 , (c) $\mathrm{t}=1.35$ and (d) $\mathrm{t}=3.15$ for $\operatorname{Pr}=0.02$ and $\mathrm{Le}=7500$

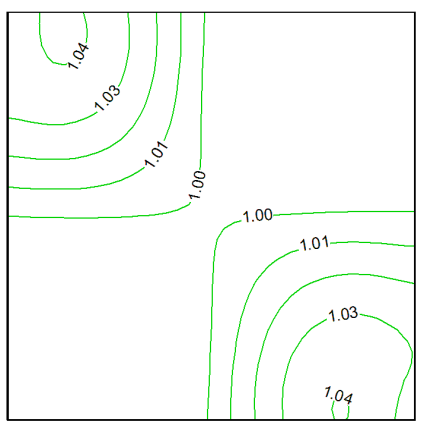

(a)

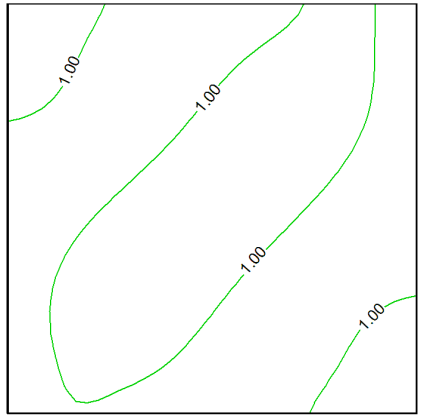

(c)

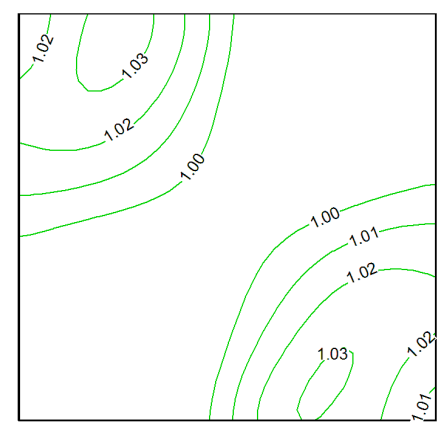

(b)

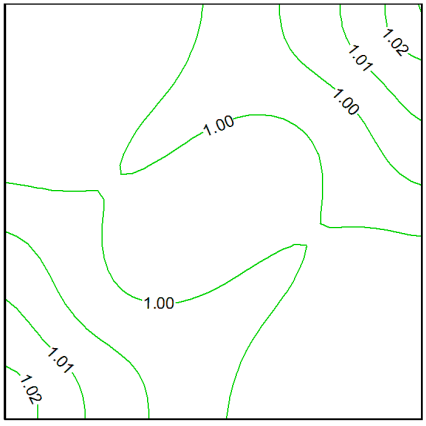

(d)
Fig. 10 Local Entropy generation due to temperature gradient irreversibility $N_{S-t h}$ for $R a=100, \mathrm{~N}=-10$ at:(a) $\mathrm{t}=0.3$, (b) $\mathrm{t}=0.75$, (c) $\mathrm{t}=1.35$ and (d) $\mathrm{t}=3.15$ for $\mathrm{Pr}=0.02$ and $\mathrm{Le}=7500$

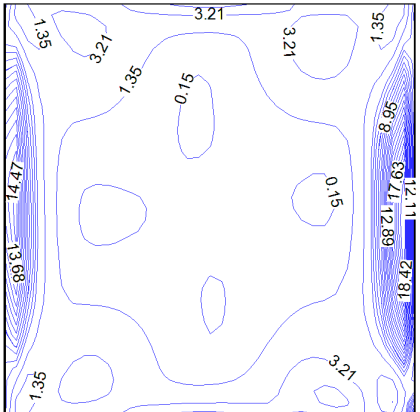

(a)

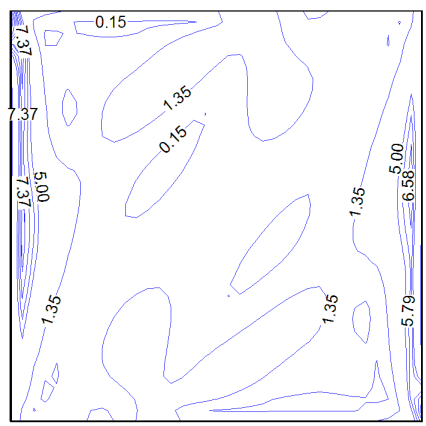

(c)

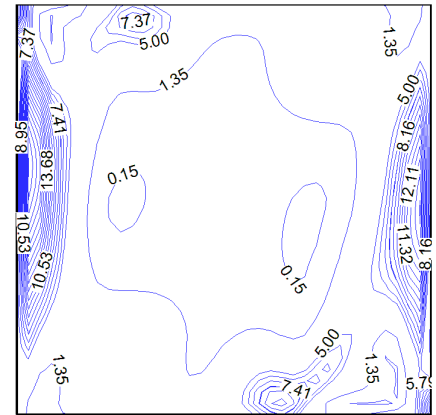

(b)

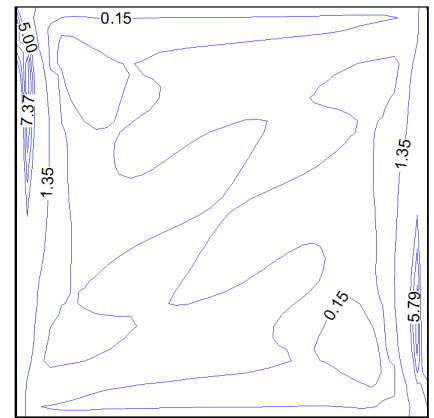

(d)
Fig. 11 Local Entropy generation due to viscous effect irreversibility $N_{S-f r}$ for $\mathrm{Ra}=100, \mathrm{~N}=-10$ at:(a) $\mathrm{t}=0.3$, (b) $\mathrm{t}=0.75$, (c) $\mathrm{t}=1.35$ and (d) $\mathrm{t}=3.15$ for $\operatorname{Pr}=0.02$ and $\mathrm{Le}=7500$

Fig. 10 shows the local entropy generation because of the gradient irreversibility with the same condition of Fig. 9. Entropy generation contours start to develop from left top and right bottom corners it penetrates into the cavity. In a similar way, local entropy generation due to viscous effect irreversibility is presented in Fig. 11 for different time steps. Finally, local entropy generation due to total irreversibility is given in Fig. 12. Based on obtained results in Fig. 11 the middle sides of the walls are active to produce entropy. On the contrary, entropy production contours are cumulated to the left top and right bottom side of the enclosure. They are presented according to time step. As seen from the figure, after $t=0.3$, distribution of local entropy generation does not change with time.

\section{CONCLUSIONS}

A computational study of unsteady double diffusive convection has been performed in a three dimensional cubical cavity filled with molten $\mathrm{Pb}-\mathrm{Sn}$. The main findings can be drawn from the obtained results as

- $\quad$ As seen from the work, the most important parameter on heat and mass transfer is buoyancy ratio. It is more effective on heat transfer than that of mass transfer.

- Number of circulation cell is directly related with $\mathrm{N}$ parameter that number of cell enhances with decreasing of $\mathrm{N}$ parameter.

- The problem must be solved for higher $\mathrm{N}$ parameter. Because two dimensional solution is not enough to understand the phenomena.

- Entropy generation increases with increasing of time step inside the cavity and left top and right bottom corners are effective on that. 

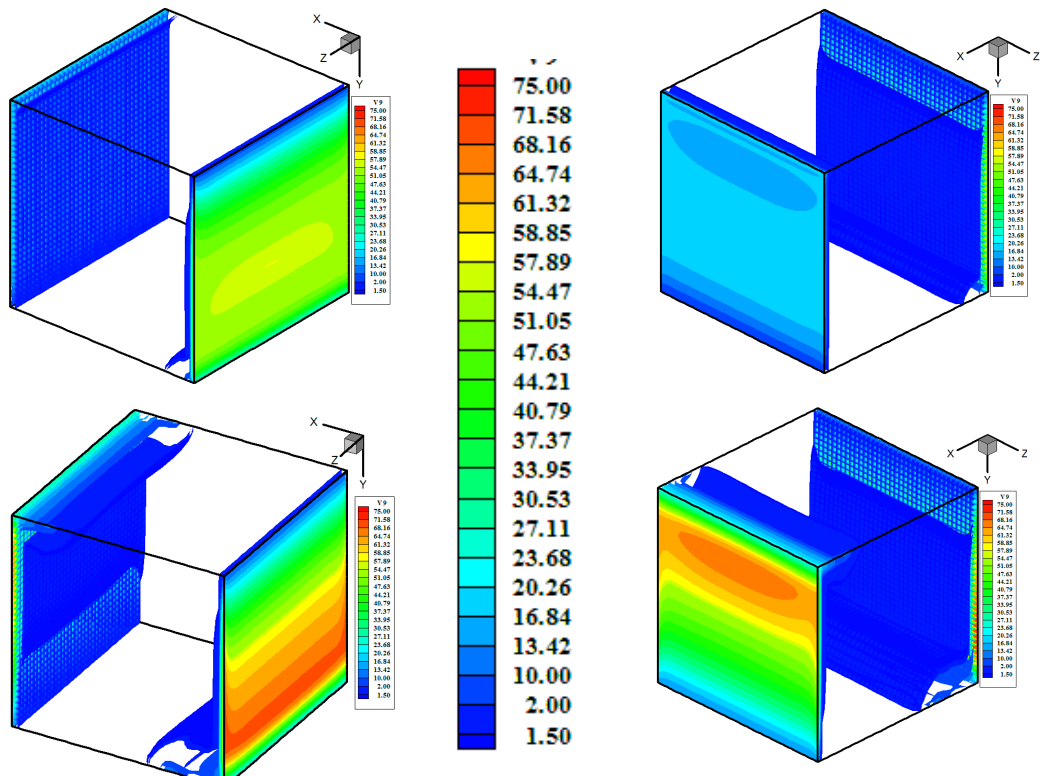

(a)
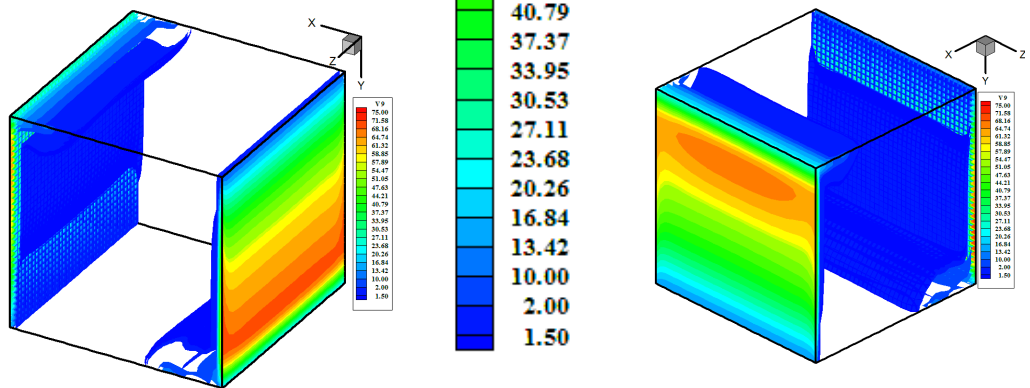

(b)
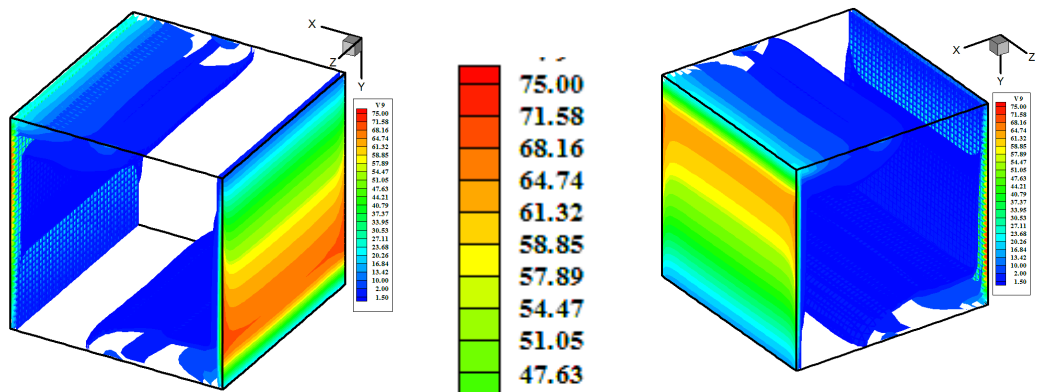

(c)
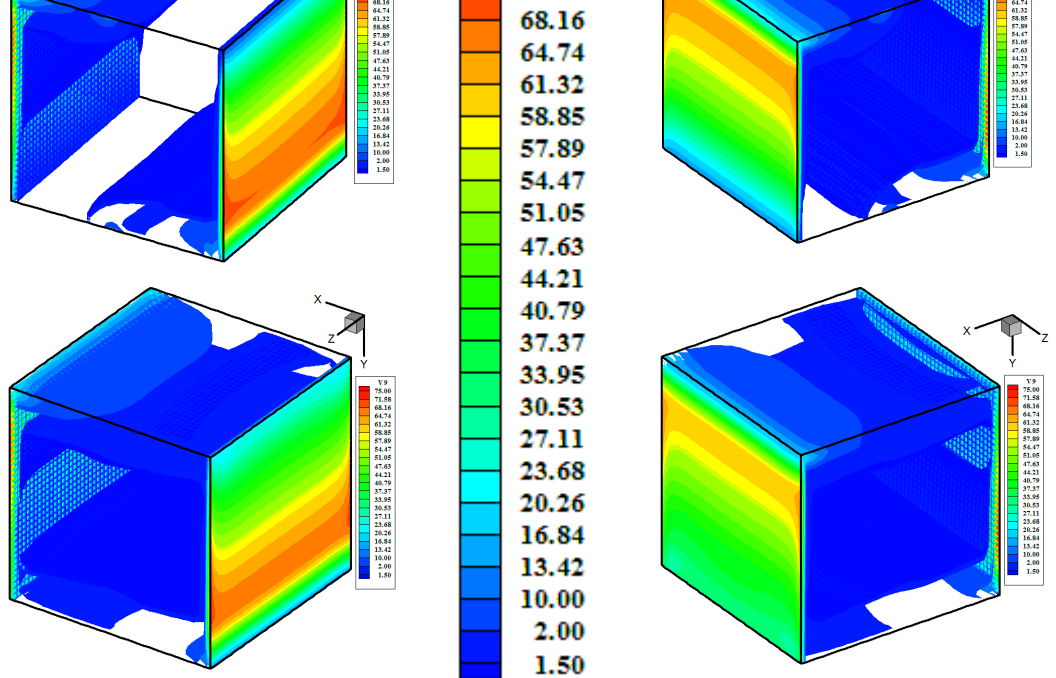

(d)

Fig. 12 Local Entropy generation due to total irreversibility $N_{S}$ for $R a=100, \mathrm{~N}=-10$ for $\operatorname{Pr}=0.02$ and $\mathrm{Le}=7500$ at $(\mathrm{a}) \mathrm{t}=0.3$, (b) $\mathrm{t}=0.75,(\mathrm{c}) \mathrm{t}=$ 1.35 and $(\mathrm{d}) \mathrm{t}=3.15$

\section{NOMENCLATURE}

$\mathrm{C}$ dimensionless species concentration $\left(C^{\prime}-C^{\prime}{ }_{l}\right) /\left(C^{\prime}{ }_{h}-C^{\prime}{ }_{l}\right)$ )

$\mathrm{C}^{\prime}{ }_{\mathrm{h}} \quad$ high species concentration

C'1 low species concentration

D species diffusivity

g acceleration of gravity

$\mathrm{k}$ thermal conductivity

Le Lewis number

$\mathrm{N}$ buoyancy ratio

$\vec{n} \quad$ unit vector normal to the control volume surface

$\mathrm{Nu} \quad$ Nusselt number

$N_{S} \quad$ dimensionless irreversibility

Pr Prandlt number

$\mathrm{R}$ ideal gas constant

$\mathrm{Ra} \quad$ Rayleigh number

$S \quad$ entropy generation

Sh Sherwood number
$\mathrm{T}$ dimensionless temperature $\left(=\left(T^{\prime}-T^{\prime}{ }_{c}\right) /\left(T^{\prime}{ }_{h}-T^{\prime}{ }_{c}\right)\right)$

$\mathrm{t} \quad$ dimensionless time $\left(=t^{\prime} \cdot \alpha / W^{2}\right)$

$\mathrm{T}_{\mathrm{h}} \quad$ hot wall temperature

T'c cold wall temperature

$\vec{u} \quad$ dimensionless velocity $\left(=\vec{u}^{\prime} \cdot W / \alpha\right)$

$\mathrm{V}$ entire volume of the cavity

W cavity side

\section{Greek symbols}

$\alpha \quad$ thermal diffusivity

$\beta_{T} \quad$ coefficient of thermal expansion

$\beta_{C} \quad$ coefficient of compositional expansion

$\mu \quad$ dynamic viscosity

$v \quad$ kinematic viscosity

$\vec{\omega} \quad$ dimensionless vorticity $\left(=\vec{\omega}^{\prime} \cdot \alpha / W^{2}\right)$

$\vec{\psi} \quad$ dimensionless stream function $\left(\vec{\psi}^{\prime} / \alpha\right)$ 


\section{Superscripts}

dimensional variable

\section{REFERENCES}

Abidi, A., Kolsi, L., Borjini, M. N., Aissia, H. B., Safi, M. J., 2008. "Effect of Heat and Mass Transfer through Diffusive Walls on ThreeDimensional Double-Diffusive Natural Convection," Numerical Heat Transfer, 53, 1357 - 1376

http://dx.doi.org/10.1080/10407780801960241

Bardan, G., Bergeon, A., Knobloch , E., Mojtabi, A., 2000, "Nonlinear Doubly Diffusive Convection in Vertical Enclosures," Physica D, 138, 91-113.

http://dx.doi.org/10.1016/S0167-2789(99)00195-5

Bennacer, R., Mohamad, A. A., Akrour, D., 2001. "Transient Natural Convection in an Enclosure with Horizontal Temperature and Vertical Solutal Gradients," Int. J. Therm. Sci., 40, 899-910. http://dx.doi.org/10.1016/S1290-0729(01)01276-5

Bergman, T. L., Hyun, M. T., 1996. "Simulation of Two-Dimensional Thermosolutal Convection in Liquid Metals Induced by Horizontal Temperature and Species Gradients," Int. J. Heat Mass Transfer, 39, 2883-2894,

http://dx.doi.org/10.1016/0017-9310(95)00385-1

Borjini, M.N., Kolsi, L., Daous, N., Aissia, H. B., 2005. "Hydromagnetic Double-Diffusive Laminar Natural Convection in a Radiatively Participating Fluid," Numerical Heat Transfer, 48, 483506.

http://dx.doi.org/10.1080/10407780590959907

Ghachem, K., Kolsi , L., Mâatki, C. , Hussein, A. K., Borjini, M. N., 2012, "Numerical Simulation of Three-Dimensional Double Diffusive Free Convection Flow and Irreversibility Studies in a Solar Distiller," International Communications in Heat and Mass Transfer, 39, 869876.

http://dx.doi.org/10.1016/j.icheatmasstransfer.2012.04.010

Ghenai, C., Mudunuri, A., Lin, C.X., Ebadian, M.A., 2003. "DoubleDiffusive Convection during Solidification of a Metal Analog System $\left(\mathrm{NH}_{4} \mathrm{Cl}-\mathrm{H}_{2} \mathrm{O}\right)$ in a Differentially Heated Cavity," Experimental Thermal and Fluid Science, 28, 23-35.

http://dx.doi.org/10.1016/S0894-1777(03)00089-X

Gholizadeh, M. M., Nikbakhti, R., Khodakhah, J., Ghasemi, A., 2016. "Numerical Study of Double Diffusive Buoyancy Forces Induced Natural Convection in a Trapezoidal Enclosure Partially Heated from the Right Ssidewall," Alexandria Engineering Journal, 55, 779-795.

http://dx.doi.org/10.1016/j.aej.2016.01.029

Ibrahim, A., Lemonnier, D., 2009. "Numerical Study of Coupled Double-Diffusive Natural Convection and Radiation in a Square Cavity Filled with a $\mathrm{N}_{2}-\mathrm{CO}_{2}$ Mixture," International Communications in Heat and Mass Transfer, 36, 197-202.

http://dx.doi.org/10.1016/i.icheatmasstransfer.2008.10.019

Maatki , C H., Ghachem , K., Kolsi, L., Borjini, M. N., Aissia, H. B., 2014. "Entropy Generation of Double Diffusive Natural Convection in a Three Dimensional Differentially Heated Enclosure," IJE Transactions B: Applications, 27, 215-226.

http://dx.doi.org/10.5829/idosi.ije.2014.27.02b.06

Maatki, C., Ghachem, K., Kolsi, L., Borjini, M.N., Aiissia, H. B., 2013. "Numerical Investigation of Three-Dimensional Thermosolutal Convection in a Cubic Enclosure under Magnetic Field" International Journal of Mechanics and Energy, 1, 3

Maatki, C., Ghachema , K., Kolsi , L., Hussein , A. K., Borjini , M.N., Aissiaa, H. B., 2016. "Inclination Effects of Magnetic Field Direction in 3D Double-Diffusive Natural Convection," Applied Mathematics and Computation, 273, 178-189.

\section{http://dx.doi.org/10.1016/j.amc.2015.09.043}

Maatki, C., Kolsi, L., Oztop, H. F., Chamkha, A., Borjini, M.N., Ben Aissia H., Al-Salem, K., 2013. "Effects of Magnetic Field on 3D Double Diffusive Convection in a Cubic Cavity Filled with a Binary Mixture," International Communications in Heat and Mass Transfer. 49, 86-95.

http://dx.doi.org/10.1016/j.icheatmasstransfer.2013.08.019

Nishimura, T., Imoto, T., Miyashita, H., 1994. "Occurrence and Development of Double-Diffusive Convection during Solidification of a Binary System," Int. J. Heat Mass Transfer, 37, 1455-1464. http://dx.doi.org/10.1016/0017-9310(94)90147-3

Nithyadevi, N., Yang, R. J., 2009. "Double Diffusive Natural Convection in a Partially Heated Enclosure with Soret and Dufour Effects," International Journal of Heat and Fluid Flow, 30, 902-910. http://dx.doi.org/10.1016/j.ijheatfluidflow.2009.04.001

Sun, H., Lauriat, G., Sun, D.L., Tao, W.Q., 2010. "Transient DoubleDiffusive Convection in an Enclosure with Large Density Variations" International Journal of Heat and Mass Transfer, 53, 615-625. http://dx.doi.org/10.1016/j.ijheatmasstransfer.2009.10.035

Teamah, M. A., 2008. "Numerical Simulation of Double Diffusive Natural Convection in Rectangular Enclosure in the Presences of Magnetic Field and Heat Source," International Journal of Thermal Sciences, 47, 237-248. http://dx.doi.org/10.1016/j.ijthermalsci.2007.02.003

Wang, J., Yang, M., He, Y., Zhang, Y., 2016. "Oscillatory DoubleDiffusive Convection in a Horizontal Cavity with Soret and Dufour Effects" International Journal of Thermal Sciences, 106, 57-69. http://dx.doi.org/10.1016/j.ijthermalsci.2016.03.012

Yang, M., Ma, N., 2005. “A Computational Study of Natural Convection in a Liquid-Encapsulated Molten Semiconductor with a Horizontal Magnetic Field," International Journal of Heat and Fluid Flow, 26, 810-816.

http://dx.doi.org/10.1016/j.ijheatfluidflow.2005.03.010

Sheikholeslami M., 2017 "Numerical Simulation of Magnetic Nanofluid Natural Convection in Porous Media," Physics Letters, 381(5), 494-503.

https://doi.org/10.1016/j.physleta.2016.11.042

Sheikholeslami M., 2017, "Magnetic Field Influence on Nanofluid Thermal Radiation in a Cavity with Tilted Elliptic Inner Cylinder," Journal of Molecular Liquids, 229, 137-147. https://doi.org/10.1016/j.molliq.2016.12.024

Sheikholeslami M., Chamkha A.J., 2017, "Influence of Lorentz Forces On Nanofluid Forced Convection Considering Marangoni Convection," Journal of Molecular Liquids, 225, 750-757.

https://doi.org/10.1016/j.molliq.2016.11.001

Sheikholeslami, M., Rokni H.B., 2017, "Numerical Modeling of Nanofluid Natural Convection in a Semi Annulus in Existence of Lorentz Force," Computer Methods in Applied Mechanics and Engineering, 317, 419-430.

https://doi.org/10.1016/i.cma.2016.12.028

Sheikholeslami M., Rokni H.B., 2017 "Nanofluid Two Phase Model Analysis in Existence of Induced Magnetic Field," International Journal of Heat and Mass Transfer, 107, 288-299.

https://doi.org/10.1016/j.ijheatmasstransfer.2016.10.130

Sheikholeslamia, M., Shehzad S.A., 2017 "Magnetohydrodynamic Nanofluid Convection in a Porous Enclosure Considering Heat Flux Boundary Condition," International Journal of Heat and Mass Transfer, 106, 1261-1269.

https://doi.org/10.1016/j.ijheatmasstransfer.2016.10.107 